\title{
Vertebroplasty in Patients with Tumour-Related Vertebral Fractures: Is Rehabilitation Needed?
}

\author{
Massimiliano Polastri ${ }^{1}$, Alessandro Gasbarrini ${ }^{2}$ \\ ${ }^{I}$ Department of Physical Medicine and Rehabilitation, Bologna University Hospital Authority, Sant'Orsola-Malpighi Polyclinic, Bologna, Italy \\ ${ }^{2}$ Department of Oncologic and Degenerative Spine Surgery, Rizzoli Orthopaedic Institute, Bologna, Italy
}

For about 20 years, vertebroplasty has been used to achieve relief from pain and improve function in eligible patients affected by vertebral fractures. The procedure is also performed in patients with tumours of the vertebral body. The aim of this study was to investigate, by means of a literature review, correlations between vertebroplasty and the need for rehabilitation after patients with tumourrelated vertebral fractures were operated on. This review was based on literature from the US National Library of Medicine, National Institutes of Health (PubMed), using the following Medical Subject Headings (MeSH) terms: "vertebroplasty," "surgical procedures minimally invasive," "bone neoplasm," "spine," "postoperative care," "rehabilitation," and "exercise." In total, 14 citations were retrieved: potentially relevant studies were identified by searching titles and abstracts, and then the full text of the selected articles was reviewed. From this review, the postoperative course of vertebroplasty today does not strictly indicate the need for rehabilitation.

Keywords: Spine; Bone neoplasm; Surgical procedures, minimally invasive; Vertebroplasty; Postoperative care

\section{Introduction}

Bone metastases occur in a high percentage of patients with cancer, causing pain and other related symptoms; progressive and nocturnal pain may be related to a malignant aetiology [1,2]. Spinal metastases may be treated surgically or non-surgically, depending on patient status [1]. The first publications on spinal metastases date to the beginning of the last century [3]. Due to the clinical presentation, a multidisciplinary approach is essential in patients with metastasis of the spinal column [4].

For approximately 20 years, vertebroplasty (VP) has been used to achieve relief from pain and improve function in eligible patients affected by vertebral fractures. The procedure is also performed in patients with tumours of the vertebral body [5-10]. In 1987, Galibert et al. [11] de- scribed the technique for the treatment of a vertebral angioma, and it was described for the treatment of vertebral metastases in 1989 by Kaemmerlen et al. [12]. A study by Brodano et al. [6] explored indications, contraindications, techniques, and complications of VP. These authors pointed out that VP is not indicated as an isolated procedure in primary spine tumours, and it should not be used when secondary a disease of the spine, severe osteoporosis, or segmental kyphosis is present. VP is contraindicated under some conditions, as pointed out by Rose and Buchowski [1]. Nevertheless, it has been generally recognised as a safe procedure for patients; the complications are known and described elsewhere [13-15]. Among the complications, cement leakage occurs frequently, causing pulmonary cement embolism. A report by Kollmann et al. [16] indicated that the removed cement piece was not

Received Jul 12, 2012; Revised Aug 22, 2012; Accepted Aug 23, 2012

Corresponding author: Massimiliano Polastri

Department of Physical Medicine and Rehabilitation, Bologna University Hospital,

Sant'Orsola-Malpighi Polyclinic, Via G. Massarenti, 9, Bologna-40138, Italy

Tel: +39-051-636-3485, Fax: +39-051-082-2185, E-mail: gbptap1@gmail.com 
Table 1. Search's criteria

\begin{tabular}{llll}
\multicolumn{1}{c}{ Strings search } & \multicolumn{1}{c}{ Limits } & \multicolumn{1}{c}{ Citations } \\
\#1 "bone neoplasm" AND "spine" & Humans-English, French, German, Italian & 7,978 \\
\#2 "vertebroplasty" OR "surgical procedures, minimally invasive" & Humans-English, French, German, Italian (published & between 1 January 2007 and 31 March 2012) & 85,757 \\
\#3 "postoperative care" OR "rehabilitation" OR "exercises" & Humans-English, French, German, Italian & 492,274 \\
\hline
\end{tabular}

thrombogenic. Furthermore, a recent study reported the effects of inhalation of polymethylmethacrylate (PMMA) fumes by the operating room staff [17]. Mpotsaris et al. [18] found that VP relieved symptoms and achieved mobility improvements and was also effective in the immediate relief of pain in patients with tumour-related vertebral fractures. In daily clinical practice, VP represents a good option in tumour-healed patients or could be considered as a palliative procedure in those for whom different solutions are not applicable, such as when a mechanical insufficiency of the vertebral bodies is present $[6,19]$. On the other hand, a previous study by Harvey and Kallmes [20] demonstrated that patients undergoing VP are discharged more frequently to rehabilitation facilities rather than home and the result suggested that rehabilitation is proposed even in cases of a good outcome. Despite the use of VP, little has been published regarding postoperative rehabilitation following the procedure in regards to tumour-related vertebral fractures. The aim of this study was to investigate, by means of a literature review, correlations between VP and the need for rehabilitation after patients with tumour-related vertebral fractures were operated on.

\section{Materials and Methods}

This review was based on literature from the US National Library of Medicine, National Institutes of Health (PubMed), using the following Medical Subject Headings $(\mathrm{MeSH})$ terms: "vertebroplasty," "surgical procedures,

\section{Limits Strings search Citations (n)}

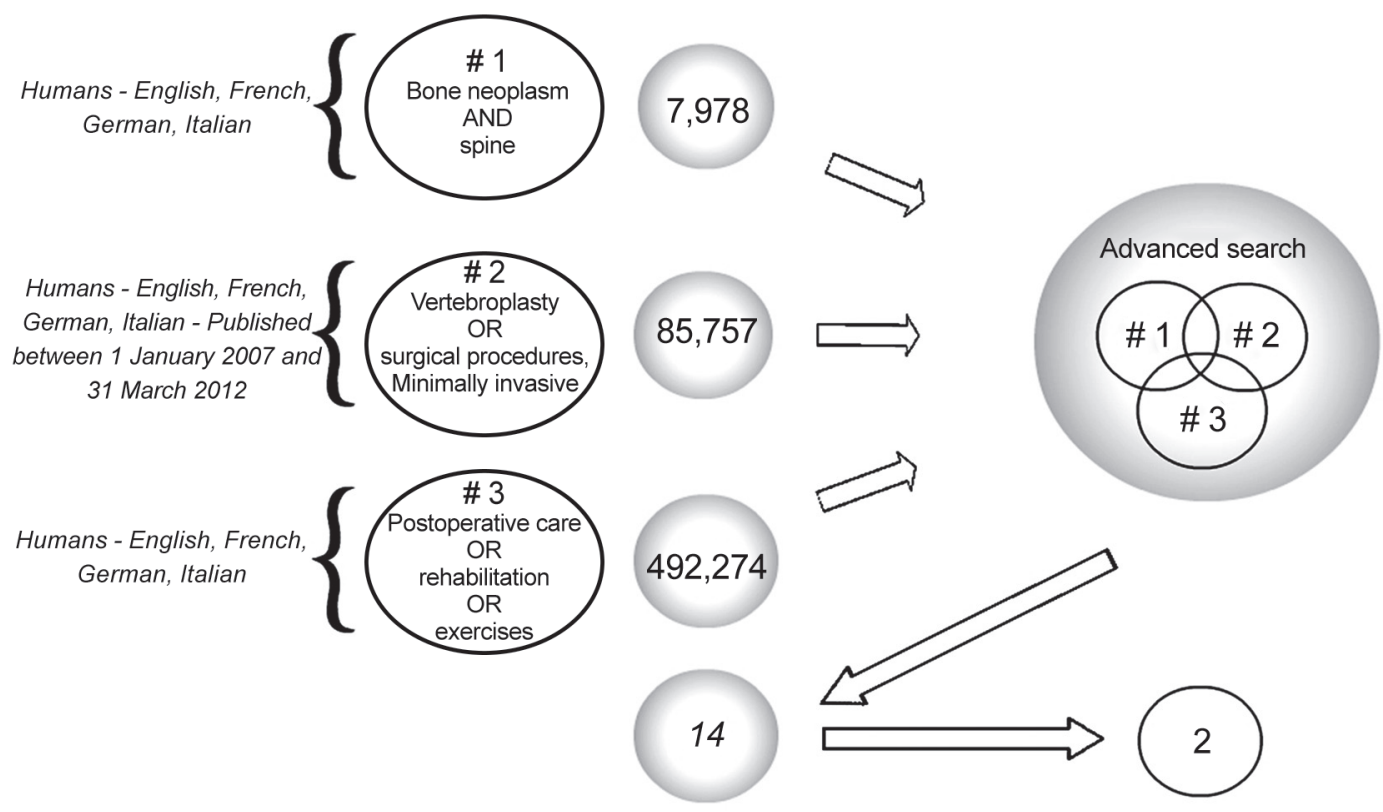

Fig. 1. Search strategy. 
Table 2. Studies included in the review of the full-text

\begin{tabular}{|c|c|c|c|}
\hline Authors & Design & Patients & Treatment \\
\hline $\begin{array}{l}\text { Pedicelli et al., } \\
2009 \text { [21] }\end{array}$ & $\begin{array}{l}\text { Non-experimental } \\
\text { (observational prospective) }\end{array}$ & $\begin{array}{l}120 \text { Patients ( } 13 \% \text { was affected by } \\
\text { primary or secondary tumour) Levels: } \\
\text { thoracic, lumbar and sacral vertebrae }\end{array}$ & $\begin{array}{l}\text { Rehabilitation is recommended } \\
\text { (hydrotherapy, proprioceptive, postural training, } \\
\text { magnetic or laser therapy) }\end{array}$ \\
\hline $\begin{array}{l}\text { Lopez-O'Rourke et al., } \\
2009 \text { [22] }\end{array}$ & $\begin{array}{l}\text { Non-experimental } \\
\text { (case report) }\end{array}$ & $\begin{array}{l}1 \text { Patient } \\
\text { Compression fracture of } \mathrm{C}_{3} \\
\text { (breast cancer metastasis) }\end{array}$ & $\begin{array}{l}\text { A rehabilitation program is cited } \\
\text { (back extensor muscle potentiating) }\end{array}$ \\
\hline
\end{tabular}

minimally invasive," "bone neoplasm," "spine," "postoperative care," "rehabilitation," and "exercise." The Boolean operators OR and AND were used with the key words. Three search strings were built and matched to obtain a selected number of citations. The first string was "bone neoplasm AND spine" using limits in the species and languages fields. The second was "vertebroplasty OR surgical procedures, minimally invasive," using limits in species, languages, and dates, in order to obtain the most recent results on the topic. The third string was "postoperative care OR rehabilitation OR exercises" with the same limits as the first. The three search strings were matched using the AND operator in the advanced search option of PubMed (Table 1). The search was conducted in April 2012. Studies were included in the review if they considered patients with bone neoplasm/spinal metastases undergoing VP, if a description of rehabilitation was present, and if they were written in English, Italian, German, or French. The search strategy is summarised in Fig. 1.

\section{Results}

In total, 14 citations were retrieved: potentially relevant studies were identified by searching titles and abstracts, and then the full text of the selected articles was reviewed. Twelve citations were excluded because they were related to techniques other than VP, did not consider vertebral fractures, and/or did not take into consideration the topic of rehabilitation. Finally, two fulltext articles were retained for review, having met the inclusion criteria. In the two studies, different vertebral levels were considered and both included a part dedicated to the rehabilitative treatment (Table 2).

\section{Discussion}

All studies retrieved in this review were non-experimen- tal in nature, most had a small or very small population, and there was little discussion of the rehabilitation needed after VP. The papers retrieved focused on surgery rather than rehabilitation. However, Pedicelli et al. [21] described the importance of postoperative rehabilitation to maximise the outcome in their sample after VP. Even though a detailed description of the rehabilitative pathway was lacking, these authors dealt with the subject to some degree and reported on the physical therapies used as postoperative tools (laser, magnetic fields). LopezO'Rourke et al. [22], in a case report, described the course of a patient with bone metastases who underwent cervical VP; the authors referred to other studies [23,24] examining the usefulness of a program to strengthen the back extensor muscles in women with osteoporosis. The authors also cited a study by Crevenna et al. [25] in which aerobic exercises were conducted in a breast cancer patient suffering from bone metastases. Even though this paper was not included in the present review because it did not satisfy the inclusion criteria (the patient did not undergo a VP), we considered the paper because the authors planned a new therapeutic approach (aerobic exercise) in a patient affected by bone metastases related to breast cancer, reporting physical and physiological benefits during the chemotherapy timeframe. It is widely known that physical activity improves health conditions in general and that it is also recommended in aging and in skeletal diseases. We would underscore the appropriateness of exercise as a primary component in rehabilitation. In accordance with the studies above, one may suppose that appropriate and controlled physical activity should improve the course of recovery after VP, in both cancer and non-cancer patients. This review extracted only the most recent information from the literature being limited to the previous years and the result should be restricted. However, this weak point could represent one of the advantages of this study in that the result was based 
on the most recent studies. We also emphasise that the non-experimental nature of the reviewed studies requires us to carefully consider the contents.

\section{Conclusions}

We have attempted to gather more evidence to better understand the need for rehabilitation after VP in cancerrelated vertebral fractures by means of a multidisciplinary review of the literature. As stated in the Introduction, a multidisciplinary approach is recommended when treating patients with spine tumours or spine metastasis, and this may include rehabilitation. We searched the literature for published studies on the topic. Notwithstanding that rehabilitation after VP in cancer patients has rarely been examined, we found that a non-specific rehabilitation pathway is described to enhance physical recovery. Even so, the need for rehabilitation after VP is not clearly described for patients with tumour-related vertebral fractures. In conclusion, VP is used to reduce pain in eligible patients with vertebral fractures and represents a good option in tumour-healed patients or in the presence of mechanical insufficiency of the vertebral bodies. A multidisciplinary approach is advisable for those suffering from vertebral fractures/pain under cancer-related conditions, and rehabilitation should be personalised and appropriate, based on the clinical condition and daily needs of the patient. From this review, today, the postoperative course of VP does not strictly indicate the need for rehabilitation. No experimental study has been reported on the topic.

\section{Conflict of Interest}

No potential conflict of interest relevant to this article was reported.

\section{Acknowledgments}

The authors thank Dr. Simonetta Righi (F.B. Bianchi Library at Alma Mater Studiorum University of Bologna, Italy) for the production of the image.

\section{References}

1. Rose PS, Buchowski JM. Metastatic disease in the thoracic and lumbar spine: evaluation and manage- ment. J Am Acad Orthop Surg 2011;19:37-48.

2. Theriault RL, Theriault RL. Biology of bone metastases. Cancer Control 2012;19:92-101.

3. Carter LJ. Spinal metastasis from breast carcinoma. Can Med Assoc J 1926;16:48-51.

4. Gasbarrini A, Beisse R, Fisher C, Rhines L. Spine metastasis. Int J Surg Oncol 2011;2011:375097.

5. Burton AW, Mendoza T, Gebhardt R, et al. Vertebral compression fracture treatment with vertebroplasty and kyphoplasty: experience in 407 patients with 1,156 fractures in a tertiary cancer center. Pain Med 2011;12:1750-7.

6. Brodano GB, Cappuccio M, Gasbarrini A, et al. Vertebroplasty in the treatment of vertebral metastases: clinical cases and review of the literature. Eur Rev Med Pharmacol Sci 2007;11:91-100.

7. Laufer I, Sciubba DM, Madera M, et al. Surgical management of metastatic spinal tumors. Cancer Control 2012;19:122-8.

8. Mikami Y, Numaguchi Y, Kobayashi N, Fuwa S, Hoshikawa Y, Saida Y. Therapeutic effects of percutaneous vertebroplasty for vertebral metastases. Jpn J Radiol 2011;29:202-6.

9. Munk PL, Murphy KJ, Gangi A, Liu DM. Fire and ice: percutaneous ablative therapies and cement injection in management of metastatic disease of the spine. Semin Musculoskelet Radiol 2011;15:125-34.

10. Visser KC, Besse K, Wagemans M, et al. Pain in patient with cancer. Pain Pract 2011;11:453-75.

11. Galibert P, Deramond H, Rosat P, Le Gars D. Preliminary note on the treatment of vertebral angioma by percutaneous acrylic vertebroplasty. Neurochirurgie 1987;33:166-8.

12. Kaemmerlen P, Thiesse P, Bouvard H, Biron P, Mornex F, Jonas P. Percutaneous vertebroplasty in the treatment of metastases: technic and results. J Radiol 1989;70:557-62.

13. Chen YJ, Chang GC, Chen WH, Hsu HC, Lee TS. Local metastases along the tract of needle: a rare complication of vertebroplasty in treating spinal metastases. Spine (Phila Pa 1976) 2007;32:E615-8.

14. Habib N, Maniatis T, Ahmed S, et al. Cement pulmonary embolism after percutaneous vertebroplasty and kyphoplasty: an overview. Heart Lung 2012;41:50911.

15. Tourtier JP, Cottez S. Images in clinical medicine. Pulmonary cement embolism after vertebroplasty. $\mathrm{N}$ 
Engl J Med 2012;366:258.

16. Kollmann D, Hoetzenecker K, Prosch H, et al. Removal of a large cement embolus from the right pulmonary artery 4 years after kyphoplasty: consideration of thrombogenicity. J Thorac Cardiovasc Surg 2012;143:e22-4.

17. Amoretti N, Coco L, Nouri Y, et al. Inhalation study of polymethyl methacrylate following radiologist exposure during percutaneous vertebroplasty. Skeletal Radiol 2013;42:203-7.

18. Mpotsaris A, Abdolvahabi R, Hoffleith B, et al. Percutaneous vertebroplasty in vertebral compression fractures of benign or malignant origin: a prospective study of 1188 patients with follow-up of 12 months. Dtsch Arztebl Int 2011;108:331-8.

19. Gasbarrini A, Cappuccio M, Mirabile L, et al. Spinal metastases: treatment evaluation algorithm. Eur Rev Med Pharmacol Sci 2004;8:265-74.

20. Harvey RE, Kallmes DF. Discharge disposition following vertebroplasty. AJNR Am J Neuroradiol 2011;32:1614-6.
21. Pedicelli A, Rollo M, Piano M, Grattacaso G, Colosimo C, Bonomo L. Percutaneous vertebroplasty: optimizing the procedure after treatment of 250 vertebral levels under fluoroscopic guidance. Radiol Med 2009;114:1141-58.

22. Lopez-O’Rourke VJ, Orient-Lopez F, Fontg-Manzano F, et al. Pathological vertebral compression fracture of C3 due to a breast cancer metastasis in a male patient. Spine (Phila Pa 1976) 2009;34:E586-90.

23. Hongo M, Itoi E, Sinaki M, et al. Effect of low-intensity back exercise on quality of life and back extensor strength in patients with osteoporosis: a randomized controlled trial. Osteoporos Int 2007;18:1389-95.

24. Huntoon EA, Schmidt CK, Sinaki M. Significantly fewer refractures after vertebroplasty in patients who engage in back-extensor-strengthening exercises. Mayo Clin Proc 2008;83:54-7.

25. Crevenna R, Schmidinger M, Keilani M, et al. Aerobic exercise for a patient suffering from metastatic bone disease. Support Care Cancer 2003;11:120-2. 